\title{
Inducible viral receptor, A possible concept to induce viral protection in primitive immune animals
}

Tirasak Pasharawipas

\begin{abstract}
A pseudolysogen $(\mathrm{PL})$ is derived from the lysogenic Vibrio harveyi $(\mathrm{VH})$ which is infected with the VHS1 (Vibrio harveyi Siphoviridae-like 1) bacteriophage. The lysogenic Vibrio harveyi undergoes an unequivalent division of the extra-chromosomal VHS1 phage genome and its VH host chromosome and produces a true lysogen (TL) and pseudolysogen (PL). The PL is tolerant to super-infection of VHS1, as is of the true lysogen (TL), but the PL does not contain the VHS1 phage genome while the TL does. However, the PL can become susceptible to VHS1 phage infection if the physiological state of the PL is changed. It is postulated that this is due to a phage receptor molecule which can be inducible to an on-and-off regulation influence by an alternating condition of the bacterial host cell. This characteristic of the PL leads to speculate that this phenomenon can also occur in high organisms with low immunity such as shrimp. This article proposes a hypothesis that the viral receptor molecule on the target cell can play a crucial role in which the invertebrate aquaculture animals can become tolerant to viral infection. A possible mechanism may be that the target cell disrupts the viral receptor molecule to prevent super infection. This concept can explain a mechanism for the prevention of viral infection in invertebrate animals which do not have acquired immunity in response to pathogens. It can guide us to develop a mechanism of immunity to viral infection in low-evolved-immune animals. Also, it can be an additional mechanism that exists in high immune organism, as in human for the prevention of viral infection
\end{abstract}

Keywords: Pseudolysogen (PL), inducible viral receptor molecule, primitive-immune animals

\section{Introduction}

Lysogenic infection of the phage-bacterium relationship is considered similar to persistent infection. According to the lambda phage, its life cycle of lytic and lysogenic infection is dependent mainly on the role of the cI and Cro proteins. The predomination of cI protein maintains the phage in lysogenic stage while the Cro protein dominates the lytic infection [1,2]. It is claimed that the presence of cI protein in the lysogenic stage prevents super-infection by other lambda phage. However, if there is any stress such as starvation, the lambda phage in the lysogenic stage prefers transformation to the lytic pathway and causes the host cell death to release the phage particles [3]. Besides the lysogenic cell which might be called specifically as true lysogen (TL), there

Correspondence: tirasak4124@yahoo.com

Microbiology Unit, Department of Medical Science, Faculty of Science, Rangsit University, Pahonyothin Rd., Pathumthani, Thailand was a report of a pseudolysogen (PL) bacterial cell which is derived from a TL bacterium cell. The PL is named because of its property to prevent super-infection as does as TL. However, the PL does not contain the phage genome as does the TL. The PL can occur only in the case that the genome of temperate phage locates extra-chromosomally, plasmid-like genome, in the lysogenic cell. If the phage genome integrates into the bacterial chromosome, as most species of temperate phages do, the PL cannot be produced. The PL is reported in Vibrio harveyi which is infected with its specific temperate phage called VHS1 (Vibrio harveyi Siphoviridaelike1) [4]. It is explained that the PL is derived from an unequivalent division of the lysogenic chromosome and the phage genome. This causes one daughter cell containing the VHS1 phage genome and becomes the TL while the other one does not contain the VHS1 phage genome and subsequently is the PL. 
It is well accepted that lysogen can tolerate (sometime called resistant, although the definition of tolerant and resistant is not exactly the same) a super-infection to the same phage. The explanation for this phenomenon has never been clearly explained. Besides, there are at least three different definitions of PL. The earliest report of PL concerns those infected cells that produce a defective phage genome as proposed by Cambell [5]. The other definition of PL is the phage that can produce spontaneously with a chromosomally integrated prophage [6]. In this article, the description of the PL is that it is derived from the unequivalent division of the lysogenic chromosome and the phage genome of the TL and can tolerate a specific phage infection without the existence of the phage genome [4,7]. This PL becomes sensitive to a VHS1 phage infection as result of a physical change such as a lowering growth condition for the PL [8]. The property of the PL that is described will be a guide line to explain the interference phenomenon and its relationship to the persistent viral infection in shrimp, cell culture and eventually human body.

\section{Interference phenomenon}

Immunity to a second phage super-infection in lysogenic bacteria is similar to the interference phenomenon of the eukaryote; the target cell which is infected with the first virus would not be infected with the second viral infection. This can happen either among the same virus or the same subgroup (Homo-viral interference) $[9,10]$. It also occurs to the diverse genera (hetero-viral interference) [11-13]. There are different explanations for this phenomenon. The first explanation is that cellular enzymes which are required for the second viral infection are inhibited by the first virus which uses up the cellular resources and prevents the second virus to replicate [14]. In another explanation, the first virus generates defective interfering particles to compete for the replication resources to prohibit a second viral infection [15-17]. In a third report, the first viral infection induces the cell to synthesize protective substances to prevent super-infection of the virus. Some of these substances are virus specific, some are non-specific $[18,19]$. Interferon has been highly believed to play a role of interference [20]. However, there is also a contradictory report [21]. Thus, the mechanism of interferon to inhibit the viral infection has never been fully explained. According to these mentioned theories, there is no conclusive evidence about the mechanism of the interference phenomenon.

On the other hand, the interference phenomenon is not always true since dual viral infection in the same cell has been reported [22,23]. This means two different viruses can infect the same cell. Moreover, triple viral infection in the same culture cell is also presented [24].
It is reported that Dengue virus, Densovirus and Japanese encephalitis virus can infect in the same mosquito cell of c6/36 cell line. Obviously, these findings suggest that the interference phenomenon does not always exist as stated. This questions why some cells show interference to viral infection while c6/36 cells can be infected with multi-viral infections as studied by Kanthong et al [24]. The reason that interference phenomenon does not occur in this case might be that the three viruses enter the c6/36 cell by different receptor molecules. The receptor usage of the Japanese encephalitis virus and Dengue virus is reported to be distinct [25]. Unfortunately, the Densovirus receptor molecule has not been reported. More study of the other dual or multiple viral infections in the same cell together with the identification of the viral receptors are the interesting subjects to study to explain this interference phenomenon.

Hence, we present the hypothesis based on the inducible viral receptor concept that the host cell disrupts the expression of the receptor molecule after the first virus enters the cell. This mechanism can prevent not only the same virus entry (homo-viral interference) but also any other viruses (hetero-viral interference) that use the same viral receptor for entry into the target cell $[26,27]$. If this mechanism is influenced by interferon, further prove is needed. The phenomenon of the polyspermy block by the egg-sperm fertilization [28] may also be applied as a similar mechanism of the viral-cell interference phenomenon. However, it should be noted that prevention of polyspermy of an egg is to control the genetic inheritance of the parent. Prevention of polyinfection of viruses in the same target cell requires further explanation.

\section{Persistent viral infection in shrimp}

In the mean time, there were independent observations in the shrimp aquaculture industry concerning the persistent infection of various viruses such as Monodon baculovirus [29], Yellow head virus [30,31], White spot virus [32,33] and Taura syndrome virus [34]. These viruses were isolated in shrimp during the first few years of a massive epidemic infection. The infected shrimp can be raised and harvested with normal size as in the uninfected shrimp [30,31]. However, the isolated viruses from these persistent viral infected shrimp cause the native shrimp to die [34]. Thus, the virulent existence of the viruses contradicts the explanation that shrimp resistance to the virus is due to viral mutation [34]. Additionally, it has been reported that these viral persistent shrimp are more sensitive to an inappropriate condition such as the high density of shrimp, the range of $\mathrm{pH}$ and oxygen amounts in the ponds [30,34]. Instead of stating that these persistent viral infected shrimp are resistant to the viruses, they should be called 'tolerant to 
the viruses' because the shrimp can exhibit tolerance only in optimal conditions [31,34]. In previous reports, it was claimed that the phenomenon of viral toleration in shrimp seems to be related to a specific mechanism. Thus, if the shrimp are tolerant to a specific virus, it would not tolerate other viral infections [30,34,35]. In addition, although shrimp do not have acquired immunity, there are some reports indicating that vaccination to some shrimp viruses is possible $[33,36]$. The mechanism to explain the vaccination for the immunity in shrimp was not explained in the report.

To explain the persistent viral infection in shrimp by the inducible receptor hypothesis; it can be explained that after viral infection into the cells of the target organ, the neighboring cells which are not infected process a mechanism to disrupt the viral receptor molecule so the virus cannot attach to them. This can prevent the virus to spread to the entire organ of shrimp to cause death. It should be mentioned that these persistent viral infected shrimp do not show any gross sign of pathogenesis of persistent viral infection and the virus can be detected by only the sensitive techniques such as the polymerase chain reaction (PCR) [34,37]. This means the amounts of the virus are very small and are limited in the persistent viral infected shrimp. However, if these persistent viral infected shrimp are raised in an inappropriate condition as mentioned above, they become infected and die more easily than the uninfected shrimp $[31,34]$.

\section{Persistent viral infection in cell culture}

In addition to using the viral inducible hypothesis to explain the appearance of PL in the VHS1-infected VH and the persistent viral infection in shrimp, the concept can be applied to interpret the report of Burivong et al [38] which concerns the cell culture of Densovirus infected C6/36 cell lines. The researchers reported that the sub-passage of the cell line for 9 passages decreases the Denzovirus persistent infection from $92 \%$ in the cell line to be about $20 \%$. The researchers assumed that the decrease of the persistent cell line may be related to an interference infection of defective mutated virus [15-17]. However, the defective viruses have never been isolated or identified. With the report of the same group of researchers in a later report [39], the Densovirus persistently infected c6/36 cells resulted in less CPE (cytopathic effect) than the naïve $c 6 / 36$ cells when they were super-challenged with the Dengue 2 virus $[38,39]$. If the result of the decrease of the Denzovirus persistent infection during the sub-passage is due to the influence of the defective interference (DI) as claimed by the researchers, Densovirus persistent cell should show similar levels of CPE with the naïve cell when both are super-challenged with the Dengue 2 virus because it should have no relationship between the existence of the DI particle of Densovirus and the Dengue 2 viral particle.

Based on the inducible viral receptor concept, the result of Burivong et al $[38,39]$ could be simply explained that the Densovirus and Dengue 2 virus share the common receptor molecule to infect the $\mathrm{c} 6 / \mathrm{c} 36$ cell [40-42]. It means that the cell which is persistently infected with the Densovirus down-regulates the common viral receptor molecule so the Dengue 2 virus can not penetrate into the Densovirus persistent cell as easier than the naive $c 6 / 36$ cell line in which the viral receptor molecules are intact and susceptible to viral attachment. Thus, the naïve cell line is more susceptible to the Dengue 2 infection than the Densovirus infected cell. However, Densovirus and Dengue virus are reported to simultaneously infect in the same cell [22-24]. The inducible viral receptor concept itself, at this moment, cannot explain and confirm the phenomenon that both interference and dual viral infection can occur in the same time. At present, the receptor molecule of Densovirus has not been identified although different researchers have reported that Dengue virus enters the target cell by various distinct types of molecules [43-46]. Accordingly, an assumption is that the Densovirus might also use more than one kind of receptor molecule as the Dengue virus does. At least one of those molecules is a common receptor molecule to allow both viruses to attach to the target cell. Thus, this can cause the interference phenomenon between the Densovirus and Dengue virus. In the mean time, the other receptor molecules are the specific receptor molecules for each virus to attach to the target cell. Although the Dengue virus and Densovirus share a common receptor molecule, both can use alternative molecules to enter the target cell if the dominant one is not present. So, both viruses can perform either interference phenomenon or dual infection. However, there is not any evidence to support this assumption.

\section{Persistent viral infection in human}

In higher animals and humans who possess acquired immunity, there are some examples of viral infection which can be explained by the viral inducible receptor hypothesis. In case of persistent chronic hepatitis B carriers, the virus particles are produced continuously without any evidence of disease but cause pathological transmission to other humans $[3,47]$. However, there is the question why the virus does not infect the neighboring cell in the liver although the viral particle is still active and can horizontally transmit to other people. Accordingly, how do the neighboring cells prevent the wide spread viral infection. As mentioned previously, there are reports concerning the generation of the 
defective interfering particles which lack the necessary component(s) to generate productive infection [15-17]. This should be questioned because although it is true that defective interfering particles are produced, the complete viral particles should also be generated and cause infection or transmission as well. The appearance of defective viral particle might be just a co-incidence of viral interference. Accordingly, the 'viral inducible receptor' hypothesis can be applied to explain this question. The neighboring cells in the liver adapt to inhibit the molecule that plays a role of viral receptor. This makes the cell tolerant to homogenous infection of the Hepatitis $B$ virus in the neighboring cell. This can also explain of the existence of chronic persistent Hepatitis B carriers who can be vulnerable (compared to normal individuals) to severe liver damage if they are exposed to the other liver causing pathological substances such as alcohol and other toxic substances [48]. However, with the viral inducible receptor hypothesis, it does not preclude the possibility that cytokine, such as interferon, might play this role to down regulate the neighboring cell and inhibit the viral infection. Although, Interferon was claimed to play the role of interference, the direct injection of interferon to prevent Hepatitis B virus has not been reported to be promising $[48,49]$. However, it is still possible that interferon plays an indirect role to regulate the viral receptor. More study is required.

\section{Conclusion}

This paper presents an additional theory of an inducible viral receptor concept that the cell, in general, can adapt itself to prevent the viral infection. This process should be named as tolerant, instead of resistant, mechanism since the cell loses its prevention mechanism if exposed to inappropriate conditions such as low resources and toxic substance. This inducible viral receptor hypothesis can be used to explain the incidences by (1) the VH-PL phenomenon, (2) the toleration to viral infection in shrimp (3) the alternative interpretation of the reports of the Densovirus persistent C6/C36 cell and (4) the persistent infection of the Hepatitis B viral particle in the carriers. Mainly, it explains that each individual cell has an ability to learn to prevent the secondary viral infection by itself after the primary viral infection. This mechanism can explain the phenomenon of the viral toleration in either the low or high immune organism. In high immune organisms, the mechanism might be the additional pathway to help the memory lymphocytes to respond to the latter viral infection more promptly and effectively. In case of the primitive immune animals which lack lymphocyte to create the memory lymphocyte to respond to prevent the secondary viral infection, the phenomenon of the inducible viral receptor can explain the incidence of viral protection by the cell toleration as witness from the incidences in $\mathrm{VH}$ and shrimp. Moreover, it can explain why some researchers found that vaccination is possible in shrimp which possess lower immunity and do not have lymphocyte to create adaptive immune response and memory cells. However, this hypothesis still cannot explain it all especially the dual or multiple infection of the viruses in the same cell. I do wish more researchers would investigate the possibility of this concept.

\section{Abbreviation}

PL: pseudolysogen; VH: Vibrio harveyi; VHS1: Vibrio harveyi siphoviridae-like 1 phage; $T L$ : true lysogen.

\section{Acknowledgements}

The author is grateful to Dr. Walter R. Miller (M.D.) for his kindness to give valuable suggestion and correction throughout this article.

\section{Authors' contributions}

TP prepares and writes up the whole manuscript. He also read and approved the final manuscript.

\section{Competing interests}

The author declares that he has no competing interests

Received: 6 January 2011 Accepted: 28 June 2011

Published: 28 June 2011

\section{References}

1. Johnson AD, Poteete AR, Lauer G, Sauer RT, Ackers GK, Ptashne M: $\lambda$ repressor and cro-components of an efficient molecular switch. Nature 1981, 294:217-223.

2. Dimmock NJ, Easton AJ, Leppard KN: Introduction to modern virology. London: Blackwell Science Ltd; 52001.

3. Campbell AM: Bacteriophages. In Fields Virology.. 4 edition. Edited by: Knipe DM, Howley PM. Philadelphia: Lippincott Williams 2001:659-682.

4. Khemayan K, Pasharawipas T, Puiprom O, Sriurairatana S, Suthienkul O, Flegel TW: Unstable lysogenic and pseudolysogen in Vibrio harveyi Siphovirus-like phage. Appl Environ Microbiol 2006, 72:1355-1363.

5. Cambell AM: Temperate phage. In Episomes modern perspective in biology. Volume 1.. 1 edition. Edited by: Halvorson HO, Roman HL, Bell EU. London: Harper 1960:15-34.

6. Williamsons SJ, Malaughlin MR, Pual JH: Interaction of the FHSIC virus with its host: lysogeny or pseudolysogeny? Appl Environ Microbio/ 2001, 67:1682-1688.

7. Pasharawipas T, Thaikua S, Sriurairatana S, Ruangpan L, Direkbusarakum S, Manopvisetcharean J, Flegel TW: Partial characterization of a novel bacteriophage of Vibrio harveyi isolated from shrimp culture ponds in Thailand. Virus Res 2005, 114:63-69.

8. Pasharawipas T, Wetchakit N, Sriurairatana S: The cycle for a Siphoviridaelike phage (VHS1) of Vibrio harveyi is dependent on the physiological state of the host. Virus Res 2008, 135:332-335.

9. Hackett AJ: A possible morphologic basis for the autointerference phenomenon in vesicular stomatitis virus. Virology 1964, 24:51-59.

10. Sarma PS, Cheong MP, Hartley JW, Huebner RJA: Viral intereference test for mouse leukemia viruses. Virology 1967, 33:180-184.

11. Hunt JM, Marcus PI: Machanism of Sindbis virus-induced intrinsic intereference with vesicular stomatitis virus replication. J Virol 1974, 14:99-109.

12. Dubovi EJ, Younger JS: Inhibition of Pseudorabies virus in replication by vesicular stomatitis viruses II activity of defective interfering particles. J Virol 1976, 18:534-541.

13. Karpf A, Lenches E, Strauss E, Strauss J, Brown D: Super-infection exclusion of alphaviruses in three mosquito cell lines persistently infected with Sindbis virus. J Virol 1997, 71:7119-7123.

14. Furman PA, Hallum JV: RNA-dependent DNA polymerase activity in preparations of a mutant of Newcastle disease virus arising from persistently infected L cells. J Virol 1973, 12:548-55. 
15. Rhode SL: Defective interferning particles of Parvoviruses H-1. J Virol 1978, 27:347-356.

16. Chen WJ, Wu HR, Chiou SS: E/NS1 modifications of Dengue 2 virus after serial passages in mammalian and/or mosquito cells. Intervirology 2003, 46:289-295.

17. Aaskov J, Buzocott K, Thu HM, Lowry K, Holmes EC: Long term transmission of defective RNA viruses in humans and Ades mosquitoes. Science 2006, 311:236-238.

18. Riedel B, Brown DT: Novel antiviral activity found in the media of Sindbs virus persistently infected mosquito (Aedes albopictus) cell cultures. J Virol 1979, 29:51-60.

19. Luo T, Brown DT: Purification and characterization of Sindbis virusinduced particle which stimulates its own production and blocks virus RNA synthesis. Virology 1993, 194:44-49.

20. Cann AJ: Principle of molecular virology. San Diego: Elsevier Academic Press; 2005.

21. Stanwick $T L$, Hallum JV: Role of interferon in six cell lines persistently infected with Rubella virus. Infect Immun 1974, 10:810-815.

22. Zhang PF, Klutch M, Muller J, Marcus-Sekura CJ: Susceptibility of the Sf9 insect cell line to infection with Adventitious viruses. Biologicals 1994, 22:205-213.

23. Kamita SG, Maeda S, Hammock BD: High frequency homolous recombination between baculoviruses involves DNA replication. J Virol 2003, 77:13053-13061.

24. Kanthong N, Kheunu N, Pattanakitsakul S, Malasit P, Flegel T: Persistent triple-virus co-infections in mosquito cells. BMC Microbiology 2010, 10:14

25. Boonsanay V, Smith DR: Entry into and production of the Japanese encephalitis virus from C6/36 cells. Intervirology 2007, 50:85-92.

26. Bergelson JM, Cunningham JA, Droguett G, Kurt-Jones EA, Krithivas A, Hong JS, Horwitz MH, Crowell RL, Finberg RW: Isolation of a common receptor for Coxsackie viruses and Adenovirus 2 and 5. Science 1997, 275:1320-1323.

27. Olofsson S, Bergström T: Glycoconjugate glycans as viral receptors. Ann Med 2005, 37:154-172.

28. Wong JL, Wessel GM: Defending the zygote: search for the ancestral animal block to polyspermy. Curr Top Dev Biol 2006, 72:1-151.

29. Halder M, Ahne W, Thomsen I: Detection of a baculovirus in the tiger prawn Penaeus monodon. Zentralbl Veterinarmed B 1989, 36:257-60.

30. Pasharawipas T, Flegel TW, Sriurairatana S, Morrison DJ: Latent yellow-head infections in Penaeus monodon and implications regarding disease tolerance in crustaceans. In Proceedings of Shrimp biotechnology: Bangkok, Thailand. Edited by: Menasveta P, Paisarnrat D, Flegel TW. National Center for Genetic Engineering and Biotechnology; 1997:45-53.

31. Flegel TW, Nielsen $L$, Thamavit V, Kongtim S, Pasharawipas T: Presence of multiple viruses in non-diseased cultivated shrimp at harvest. Aquaculture 2004, 240:55-68.

32. Withyachummarnkul B: Result from black tiger shrimp Penaeus monodon culture ponds stocked with post-larvae PCR-positive or negative for white-spot syndrome virus (WSSV). Dis Aquat Organ 1999, 38:107-114.

33. Witteveldt J, Vlak JM, van Hulten MC: Increased tolerance of Litopenaeus vannamei to white spot syndrome virus (WSSV) infection after oral application of the viral envelope protein VP28. Dis Aquat Organ 2006, 70:167-170.

34. Flegel TW: Update on viral accommodation a model for host-viral interaction in shrimp and other arthropods. Dev Comp Immunol 2007, 31:217-231.

35. Schmaljohn C, Blair CD: Persistent infection of cultured mammalian cells by Japanese Encephalitis virus. J Virol 1977, 24:580-589.

36. Witteveldt J, Carolina CCifuentes, Just MVlak, van Hulten MCW: Protection of Penaeus monodon against White Spot Syndrome Virus by Oral Vaccination. J Virol 2004, 78:2057-2061.

37. Tang KF, Lightner DV: Detection and quantification of infectious hypodermal and hematopoietic necrosis virus in penaeid shrimp by real-time PCR. Dis Aquat Organ 2001, 44:79-85.

38. Burivong P, Pattanakitsakul SN, Thongrungkiat S, Malasit P, Flegel TW: Markedly reduced severity of Dengue virus infection in mosquito cell cultures persistently infected with Aedes albopictus Densovirus (AalDNV). Virology 2004, 329:261-269.

39. Kanthong N, Khemnu N, Sriurairatana S, Thongrungkiat S, Malasit P, Flegel T: Mosquito cells accommodate balances persistent co-infections with a densovirus and Dengue virus. Dev Comp Immunol 2008, 32:1063-1075.
40. White LA: Susceptibility of Aedes albopictus $\mathrm{C} 6 / 36$ cells to viral infection. J Clin Microbiol 1987, 25:1221-1224.

41. Wei W, Shao D, Huang X, Li J, Chen H, Zhang Q, Zhang J: The pathogenicity of mosquito densovirus (C6/36DNV) and its interaction with dengue virus type II in Aedes albopictus. Am J Trop Med Hyg 2006, 75:1118-1126.

42. Ren J, Ding T, Zhang W, Song J, Ma W: Does Japanese encephalitis virus share the same cellular receptor with other mosquito-borne flaviviruses on the C6/36 mosquito cells? Virol J 2007, 4:83.

43. Jindadamrongwech S, Thepparit C, Smith DR: Identification of GRP 78 (BiP) as a liver cell expressed receptor element for dengue virus serotype 2. Arch Virol 2004, 149:915-927.

44. Srikiatkhachorn A, Ajariyakhajorn C, Endy TP, Kalayanarooj S, Libraty DH, Green S, Ennis FA, Rothman AL: Virus-induced decline in soluble vascular endothelial growth receptor 2 is associated with plasma leakage in dengue hemorrhagic Fever. J Virol 2007, 81:1592-1600.

45. Salas-Benito J, Reyes-Del Valle J, Salas-Benito M, Ceballos-Olvera I, Mosso C, del Angel RM: Evidence that the 45-kD glycoprotein part of a putative dengue virus receptor complex in the mosquito cell line $\mathrm{C} 6 / 36$ is a heat-shock related protein. Am J Trop Med Hyg 2007, 77:283-290.

46. Miller $\mathrm{J}$, de Wet BJ, Martinez-Pomares L, Radclifft CM, Dwek RA, Rudd PM, Gordon S: The mannose receptor mediates dengue virus infection of macrophages. PLoS Pathog 2008, 4:e17.

47. Lin X, Robinson NJ, Thursz M, Rosenberg DM, Weild A, Pimenta JM, Hall AJ: Chronic hepatitis B virus infection in the Asia-Pacific region and Africa: review of disease progression. J Gastroenterol Hepatol 2005, 20:833-843.

48. Kojiro M: Pathology of Hepatocellular carcinoma. In Liver cancer. Edited by: Okuda K, Tobors E. New York: Churchill Livingstone; 1997:165-187.

49. Jaboli MF, Fabbri C, Liva S, Azzaroli F, Nigro G, Giovanelli S, Ferrara F, Miracolo A, Marchetto S, Montagnani M, Colecchia A, Festi D, Reggiani LB, Roda E, Mazzella G: Long-term alpha interferon and lamivudine combination therapy in non-responder patients with anti-HBe-positive chronic hepatitis B: results of an open controlled trial. World J Gastroenterol 2003, 9:1491-1495.

doi:10.1186/1743-422X-8-326

Cite this article as: Pasharawipas: Inducible viral receptor, A possible concept to induce viral protection in primitive immune animals. Virology Journal 2011 8:326.

\section{Submit your next manuscript to BioMed Central and take full advantage of:}

- Convenient online submission

- Thorough peer review

- No space constraints or color figure charges

- Immediate publication on acceptance

- Inclusion in PubMed, CAS, Scopus and Google Scholar

- Research which is freely available for redistribution

Submit your manuscript at www.biomedcentral.com/submit
C Biomed Central 